\title{
Patient outcome after aortic valve replacement with a mechanical or biological prosthesis: Weighing lifetime anticoagulant-related event risk against reoperation risk
}

\author{
Martijn W. A. van Geldorp, MD, MSc, ${ }^{a}$ W. R. Eric Jamieson, MD, ${ }^{c}$ A. Pieter Kappetein, MD, PhD, ${ }^{a}$ Jian Ye, MD, ${ }^{c}$ \\ Guy J. Fradet, MD, ${ }^{c}$ Marinus J. C. Eijkemans, PhD, ${ }^{\mathrm{b}}$ Gary L. Grunkemeier, PhD, ${ }^{\mathrm{d}}$ Ad J. J. C. Bogers, MD, PhD, ${ }^{\mathrm{a}}$ and \\ Johanna J. M. Takkenberg, MD, $\mathrm{PhD}^{\mathrm{a}}$
}

Objective: Although the results of aortic valve replacement with different valve prostheses are well documented in terms of survival, the risks of (valve-related) events are less well explored.

\begin{abstract}
Methods: We used a dataset of 3934 patients who underwent aortic valve replacement with either a bioprosthesis $(73 \%)$ or a mechanical prosthesis $(27 \%)$ between 1982 and 2003 to simulate the outcome of patients after aortic valve replacement with either valve type. With the use of microsimulation, we compared total age and genderspecific life expectancy, event-free life expectancy, reoperation-free life expectancy, lifetime risks of reoperation, and valve-related events for both valve types.
\end{abstract}

Results: The total follow-up was 26,467 patient-years. The mean follow-up was 6.1 years in the biological arm and 8.5 years in the mechanical arm. The mean age at implantation was 70 and 58 years for biological and mechanical prostheses, respectively, and the percentage of concomitant coronary artery bypass grafting was $47 \%$ and $28 \%$, respectively. For a 60 -year-old man, simulated life expectancy in years for biological versus mechanical prostheses was 11.9 versus 12.2 , event-free life expectancy was 9.8 versus 9.3 , and reoperation-free life expectancy was 10.5 versus 11.9 . Lifetime risk of reoperation was $25 \%$ versus $3 \%$. Lifetime risk of bleeding was $12 \%$ versus $41 \%$.

Conclusion: Even for patients aged 60 years, event-free life expectancy is better with a bioprosthesis. Although the chance of reoperation is higher, the lifetime risk of bleeding is lower compared with a mechanical prosthesis. Comparing lifetime event risks between different types of valve prostheses provides more insight into patient outcome after aortic valve replacement and aids patient selection and counseling.

Supplemental material is available online.

Biological and mechanical valve prostheses are the most commonly used valve substitutes for replacement of the native aortic valve. Each valve type has its own advantages and drawbacks. The risk of reoperation for structural valve deterioration (SVD) in patients with a biological valve increases with time and decreases with advancing age. In contrast,

\footnotetext{
From the Departments of Cardiothoracic Surgery ${ }^{\mathrm{a}}$ and Public Health, ${ }^{\mathrm{b}}$ Erasmus University Medical Center, Rotterdam, The Netherlands; University of British Columbia, ${ }^{\mathrm{c}}$ Vancouver, Canada; and Providence Health System, ${ }^{\mathrm{d}}$ Portland, Oregon.

Disclosures: Dr Jamieson received grants in aid to facilitate the research data used in this article. Dr Fradet is a consultant for Medtronic and member of the advisory board of Biotronic and Bayer. The other authors have nothing to disclose.

The authors had full access to the data and take responsibility for their integrity. All authors have read and agree to the article as written.

Received for publication Feb 26, 2008; revisions received Aug 5, 2008; accepted for publication Sept 11, 2008

Address for reprints: Martijn W. A. van Geldorp, MD, MSc, Department of Cardiothoracic Surgery, Erasmus Medical Center, Room Bd 575, PO Box 2040, 3000 CA Rotterdam, The Netherlands (E-mail: m.vangeldorp@erasmusmc.nl).

J Thorac Cardiovasc Surg 2009;137:881-6

$0022-5223 / \$ 36.00$

Copyright (c) 2009 by The American Association for Thoracic Surgery

doi:10.1016/j.jtcvs.2008.09.028
}

patients with a mechanical prosthesis require lifelong anticoagulation, and the risk of bleeding events increases with advancing age.

Outcome after aortic valve replacement (AVR) with either valve type is well documented in the literature. These results are mostly described in terms of cumulative survival, freedom from events and reoperation, and linearized occurrence rates of valve-related complications and their consequences. A patient's lifetime risk of having a (valve-related) event after AVR is less well explored. Estimations of survival and valve-related event risk for an individual patient after AVR are difficult to determine using standard time-to-event analyses. ${ }^{1}$ Nevertheless, these parameters are important in counseling a patient. The goal of this study was to calculate detailed and age-specific patient outcome after AVR with mechanical and biological prostheses by using microsimulation.

\section{MATERIALS AND METHODS \\ Patients \\ A report on a large single-center dataset on outcome after AVR from Vancouver, Canada, was published using standard methods of data analy- sis. ${ }^{2}$ For the input of the microsimulation model, we used essentially the same primary dataset but excluded reoperations and operations with con- comitant procedures other than coronary artery bypass grafting, leaving 3934 primary AVR procedures. Table 1 summarizes the dataset.}




\section{Abbreviations and Acronyms \\ $\mathrm{AVR}=$ aortic valve replacement \\ $\mathrm{CAD}=$ coronary artery disease \\ SVD $=$ structural valve deterioration}

\section{Methods}

A microsimulation model was used to simulate the lives of patients after AVR. A microsimulation model is a computer model that simulates a representative population at the individual patient level. This simulation model offers a complementary tool to standard methods of outcome analysis by simulating the lives of virtual patients until death and taking into account all complications that may occur over time (including repeating events, changing hazards over time, or with the occurrence of prior events). The model can provide insight into age- and sex-specific life expectancy and gives detailed information on the lifetime risk of valve-related events. Detailed descriptions on how to construct, test, and run this model have been published. ${ }^{3-5}$ The model can be downloaded at www.cardiothoracicresearch.nl.

Model input. The data needed to run the microsimulation model comprise the following: 1) occurrence of valve-related events and their outcome, 2) operative and reoperative mortality, 3) background mortality of the general population, and 4) excess mortality. Valve-related events were defined in accordance with the guidelines. ${ }^{6}$

1. By using the Vancouver dataset, we calculated occurrence rates of valve-related events and their outcome (eg, death and reoperation) The results are shown in Appendix E1 (Table E2). For most events, linearized occurrence rates were calculated, but a Weibull function was constructed for the occurrence of SVD. For bleeding, we assumed an age-dependent incidence and mortality, described below.

The cumulative risk of SVD in a bioprosthesis decreases with increasing age of the patient at valve implantation and increases subexponentially with time elapsed since implantation. ${ }^{7}$ Grunkemeier and colleagues ${ }^{8}$ and Thoman and colleagues ${ }^{9}$ have shown that the Weibull distribution, a generalization of the exponential distribution, is efficient in summarizing SVD in biological valves. The formula for the hazard of SVD is: $\mathrm{h}(\mathrm{t})=\mathrm{e}^{-(\mathrm{t} / \sigma)^{\wedge} \beta}$. On the basis of the Vancouver dataset, we estimated the parameters of this distribution. The value of the scale $(\sigma)$ parameter of the Weibull model was fitted to represent SVD and depended on age: $\sigma=\mathrm{e}^{2.209+0.0153 * \text { age }}$. The shape parameter $(\beta)$, which reflects the changing risk over time, was estimated at 3.211 .

The incidence risk of bleeding increases with advancing age, especially in patients with a mechanical valve who require lifelong anticoagulation. The occurrence of bleeding in the biological group was modeled as an age-dependent hazard of 0.076 with an age-dependent mortality of $0.0345{ }^{10}$ For the mechanical group, a Gompertz distribution was used $(\gamma=0.076 ; \lambda=-8.71){ }^{11}$

Because the risk of prosthetic valve endocarditis early after valve replacement is higher than later on, 2 phases of constant risks were used for prosthetic valve endocarditis. The linearized occurrence rate of the first phase, until 6 months after AVR, has an odds ratio of 5.8 for mechanical bioprostheses and 6.7 for biological bioprostheses compared with the second phase. These numbers are obtained from an earlier meta-analysis. ${ }^{12}$ The linearized occurrence rate of the second period was derived from the Vancouver dataset.

2. Operative mortality was calculated as $2.7 \%$ for a 40 -year-old man, increasing with an odds ratio of 1.034 for age (per year). ${ }^{11}$ This corresponds to a $5.0 \%$ mortality for a 60 -year-old man. For each reoperation, an additional odds ratio of 1.7 was used. ${ }^{4,12-14}$ This odds ratio corresponds with the odds ratio of 1.6 that the STS risk calculator ${ }^{15}$ and Rankin and colleagues ${ }^{16}$ used to calculate the risk of primary versus secondary AVR.
TABLE 1. Summary dataset description

\begin{tabular}{lcc}
\hline & \multicolumn{2}{c}{ Mechanical } \\
& Bioprosthesis & prosthesis \\
\hline No. of patients & 2860 & 1074 \\
Percentage of total dataset & 72.7 & 27.3 \\
Follow-up (patient-y) & 17,352 & 9,115 \\
Mean follow-up (y) & 6.1 & 8.5 \\
Mean age (y) & 70.0 & 57.6 \\
Male (\%) & 65.7 & 71.4 \\
CABG (\%) & 47.3 & 27.7 \\
Atrial fibrillation (\%) & 7.0 & 9.7 \\
Prosthesis brands (\%) & & \\
Carpentier-Edwards supra-annular valve & 56.5 & 0 \\
$\quad$ porcine (Irvine, Calif) & & \\
Carpentier-Edwards Perimount pericardial & 23.0 & 0 \\
Medtronic Mosaic porcine (Minneapolis, & 20.5 & 0 \\
$\quad$ Minn) & & \\
St Jude Medical (St Paul, Minn) & 0 & 53.3 \\
CarboMedics Inc (Austin, Tex) & 0 & 46.7 \\
\hline CABG, Coronary artery bypass grafting.
\end{tabular}

3. The background mortality, which is the mortality experienced by the normal population, is the equivalent of the life expectancy in the normal population. This was calculated using age- and sex matched American life tables derived from the Vital Statistics of the United States 1992, from the Centers for Disease Control and Prevention and the National Center for Health Statistics. ${ }^{17}$ The life expectancy curves of the normal American, British Columbian, and United Kingdom male populations are shown in Figure $1,{ }^{17-19}$ which also displays the microsimulation-calculated life expectancy after AVR.

4. The excess mortality is the mortality difference between the general population and patient population that cannot be accounted for by valve-related events but can be ascribed to increased occurrence of sudden death, underreporting of valve-related events, and underlying pathology such as left ventricular hypertrophy. ${ }^{13,20}$ The hazard ratios after AVR are previously estimated as $2.9,1.8,1.2$, and 0.8 for male patients aged $45,55,65$, and 75 years, respectively. ${ }^{12}$

Model validation. To assess the validity of the microsimulation model predictions, the microsimulation-calculated survival for patients with mechanical or biological prostheses was compared with the observed survival in the Vancouver dataset (internal validation). For external validation of the biological valve simulations, a dataset from Portland, Oregon, was used. ${ }^{21}$ The simulations of the mechanical valves were validated by comparison with a dataset on patients with mechanical valves in the United Kingdom Heart Valve Registry. ${ }^{22}$

Sensitivity analysis. One-way sensitivity analysis was performed to study the effect of changing one of the input parameters on model outcome (eg, life expectancy, event-free life expectancy, reoperation-free life expectancy, and lifetime risk of events). The baseline estimates of the valve-related events were varied by $25 \%$ to obtain favorable and unfavorable outcomes for a 60 -year-old man after AVR.

\section{RESULTS}

As shown in Figure 1, life expectancy after AVR is comparable for biological and mechanical prostheses for patients among all studied ages. Also, life expectancy after AVR is substantially lower than the life expectancy of the general population, especially in the younger age groups. Life expectancy of the normal population differs between different 


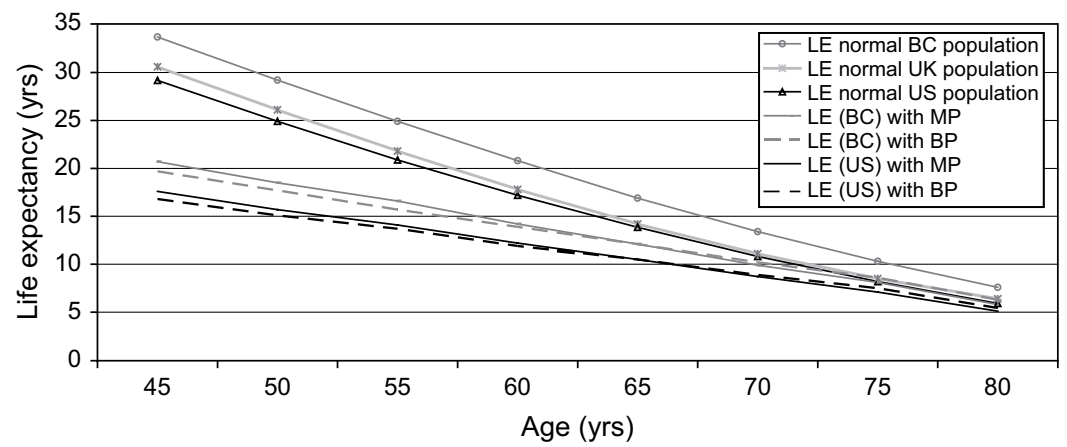

FIGURE 1. Life expectancy in men of different ages in British Columbia (BC), Canada, the United Kingdom (UK), and the United States (US) versus life expectancy after AVR in British Columbia and the United States. $L E$, Life expectancy; $M P$, mechanical prosthesis; $B P$, biological prosthesis.

countries (Canada $>$ United Kingdom $>$ United States). ${ }^{17-19}$ The differences in life expectancy between these countries disappear with increasing age.

The lifetime risk of reoperation is higher in patients with bioprostheses than in patients with mechanical valves, but the anticoagulation-related bleeding risk is higher in patients with mechanical prostheses (Figure 2). The risk of a bleeding event in the bioprosthesis group is approximately $12 \%$ in a 60 -year-old man. The lifetime risk of reoperation in the mechanical group is approximately $3 \%$ in a 60 -year-old man.

For patients aged more than 60 years of age, event-free life expectancy is better with a bioprosthesis (Figure 3), mainly because lifetime bleeding risk is lower. As shown in Figure 2, at age 60 years, the bleeding risk in patients with a mechanical prosthesis is already higher than the reoperation risk would be if a patient of the same age received a bioprosthesis. Please note that in the Vancouver dataset, the observed mortality after a bleeding event was $22 \%$. In contrast, the mortality after a reoperation for SVD $(n=137)$ was $7.3 \%$. The mean age of this patient group was 54 years.

\section{Internal Validation}

Figure E1, A presents the overall observed survival for patients with bioprostheses or mechanical prostheses in the Vancouver dataset versus the simulated survival of male patients aged 70 years with a bioprosthesis and patients aged 58 years with a mechanical prosthesis. These are the mean ages of the respective groups. Figure E1, $B$ and $C$ present the internal validation subdivided for each age group for biological and mechanical valves, respectively. Although validation appears adequate for the average patient in the dataset, a systematic underestimation of survival was observed in the simulated survival output, particularly in the subgroups of older patients with mechanical valves.

\section{External Validation}

Figure E2, $A$ depicts the external validation of survival of patients with a bioprosthesis. Figure E2, $B$ describes the external validation of the survival of patients with a mechanical prosthesis.

\section{Sensitivity Analyses}

Tables E2 and E3 shows the summary of the 1-way sensitivity analysis for bioprostheses and mechanical prostheses. Variation of the input parameters of the model yielded only relatively small changes in the output, except for changes in the hazard ratios for excess mortality and to a lesser extent changes in median time to SVD. Changing background populations has an effect on the event free life-expectancy estimates which is shown in Figure E3, A. The level of uncertainty of the age cut-off point at which a bioprosthesis is preferable over a mechanical prosthesis is displayed in Figure E3, $B$.

\section{DISCUSSION}

The estimates of lifetime patient risk of nonfatal events are obtained using cumulative incidence analysis. Sometimes Kaplan-Meier analysis is incorrectly used for this purpose. The issue of the appropriate use of actuarial (Kaplan-Meier) and actual analyses has been highlighted in several publications. ${ }^{23,24}$ For the present article the differences in results with either analysis are illustrated in Figure E4. Actuarial analysis of all-cause reoperation in the Vancouver bioprosthesis group would give a cumulative risk estimate of

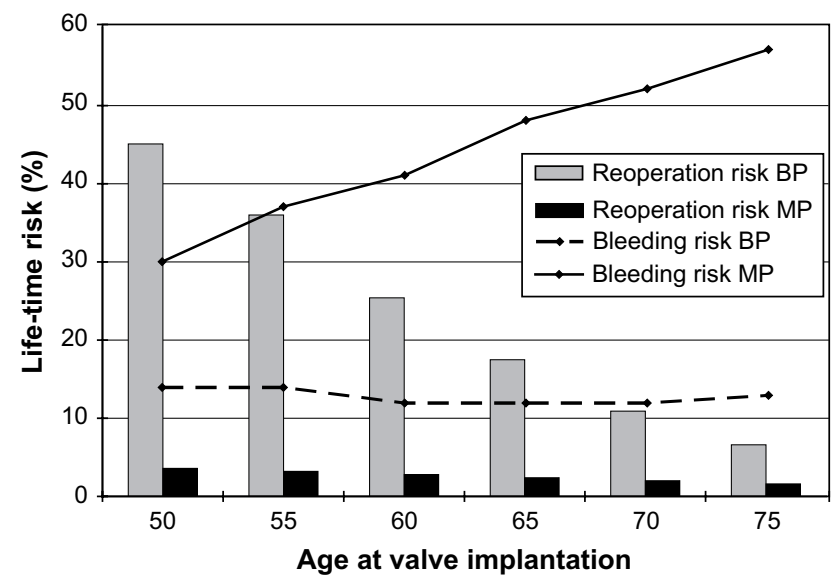

FIGURE 2. Lifetime risks of reoperation and bleeding after AVR with mechanical and bioprostheses. $B P$, Bioprosthesis; $M P$, mechanical prosthesis. 


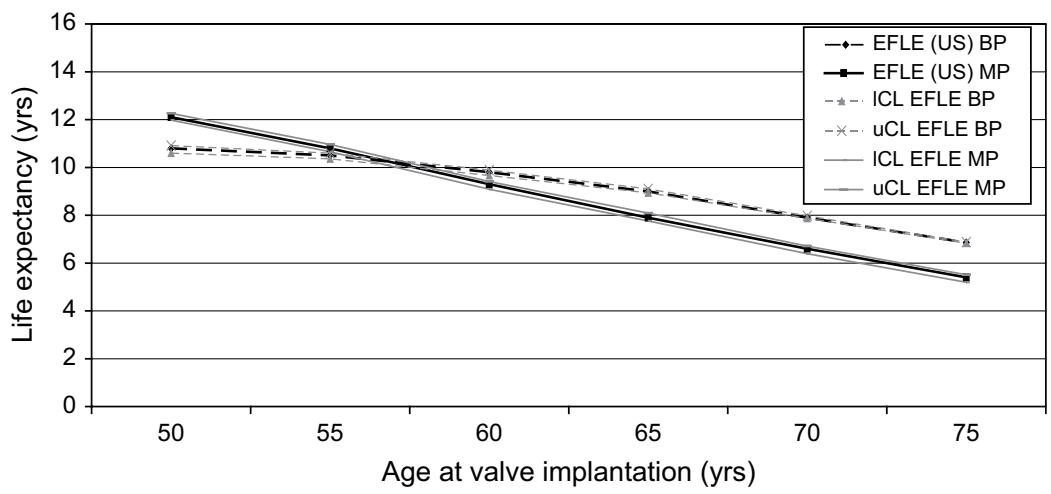

FIGURE 3. Event-free life expectancy (with $68 \%$ confidence limits in grey) after AVR with mechanical and bioprostheses in the United States. $M P$, Mechanical prosthesis; $B P$, biological prosthesis; $E F L E$, event-free life expectancy; $u C L$, upper confidence limit; $l C L$, lower confidence limit.

$30 \%$ at 15 years, clearly higher than the cumulative incidence ("actual") value, which is $16 \%$ at 15 years.

Total life expectancy after AVR is not different whether the patient receives a mechanical valve or a bioprosthesis. Because reoperation-free life expectancy, event-free life expectancy, and lifetime event risks do differ between both patient groups, these are more important factors in choosing which valve substitute should be implanted in a particular patient.

For patients aged more than 60 years, event-free life expectancy is better with a bioprosthesis, mainly because the risk of bleeding with a bioprosthesis is lower compared with a mechanical valve. Of course this is at the cost of the higher risk of a reoperation for SVD. However, the lifetime risk of a reoperation for a 60-year-old man in whom a biological valve is implanted is only $25 \%$ (risk of reoperation because of SVD is $22 \%$ ), so three quarters of the 60 year-old patients will never experience a reoperation. The lifetime risk of a bleeding event when the same patient would have a mechanical valve implanted is as high as $41 \%$. The overall observed mortality of a bleeding event in the Vancouver dataset was $22 \%$, which implies that these bleedings are life-threatening events. In contrast, the mortality risk after reoperation for SVD was $7.3 \%$ in this dataset, certainly not negligible but far lower than the mortality of bleeding. This is in accordance with an earlier report on the same dataset. ${ }^{25}$

As can be seen in Table 1, coronary artery disease (CAD) occurs more frequently in the bioprosthesis group, probably because the mean age is higher. Previous publications have shown that performing additional coronary artery bypass grafting does not have a significant impact on the crossing points of the life expectancy and event-free life expectancy curves. ${ }^{26}$ Patients who have CAD have a shorter life expectancy than those without CAD. Because of this shorter life expectancy, both the lifetime risk of a reoperation in the bioprosthesis group and the lifetime risk of bleeding and thromboembolic events in the mechanical group are lower compared with patients without CAD. The end result is that the age cutoff point at which a bioprosthesis is preferable over a mechanical prosthesis does not change and therefore does not affect prosthetic valve selection.

The American College of Cardiology/American Heart Association guidelines generally recommend implantation of a bioprosthesis for patients aged more than 65 years. ${ }^{27}$ Guided by the simulation data presented in this study, patients in younger age groups, even at approximately 60 years of age, may benefit more from a biological prosthesis than a mechanical prosthesis. This is in agreement with the report by Chan and colleagues, ${ }^{2}$ which is based on a standard analysis of the same patient population. Newer biological prostheses may show more reduction in the need for reoperation for SVD and thus lower the threshold for implantation of a bioprosthesis more.

To reduce bleeding complications, more emphasis should be put on new anticoagulation strategies, new mechanical valve prostheses that require lower international normalized ratio target rate, or lowering the age threshold for implantation of a bioprosthesis. The negative aspect of lowering this threshold is that not only more patients but also older patients will require a reoperation. This of course may increase the reoperative mortality. On the other hand, new less-invasive techniques to replace the aortic valve are rapidly emerging in cardiothoracic fields. The first reports on percutaneous and transapical approaches to replace the aortic valve are promising, and their use is expected to increase. ${ }^{28,29} \mathrm{Al}-$ though experience with these techniques is rather limited and each approach seems to have its own advantages and disadvantages, their potential is not limited to treat native aortic valve disease. Most likely these techniques are also applicable to replace deteriorated biological prostheses, the "valve-in-valve" concept. ${ }^{30}$ This could reduce operative morbidity and mortality in high-risk subsets of patients and may therefore offer a solution for the treatment of elderly patients who experience SVD. In contrast, currently it seems the awareness of surgeons that SVD may occur after implantation of a biological valve is far greater than the awareness of the incidence and impact of bleeding events 
after implantation of a mechanical valve. This gap in knowledge may affect the valve selection process.

\section{Limitations}

Microsimulation is capable of accurate and precise simulations, as long as the input of the model is based on significantly large and, more important, high-quality datasets. The quality of the model output is directly dependent on the quality of the input. The data to feed microsimulation models are usually derived from historical cohorts with a considerable follow-up and may not necessarily be applicable to 21 st century practice. For instance, the mean age of the patients who underwent reoperation is low, which implies the patients were young when they received their biological valves, reflecting surgical practice in the 1980s. Currently, few young patients receive a bioprosthesis. Also, the age-specific operative mortality estimates by the model are based on previous meta-analyses performed several years ago, and at the moment these estimates seem high. Perhaps new estimates should be established, although the effect of operative mortality on long-term outcome and life expectancy is only small, as can be seen in the sensitivity analyses (Tables E2 and E3). Further, it can be argued that current valve prostheses have the same occurrence rates as prosthetic valves that were implanted in the past. It is possible that rates are lower now. Despite this drawback, the Vancouver database consists of high-quality data on an extensive number of patients who were interviewed by annual telephone calls and whose medical records (including echocardiograms) were reviewed to check if any events had occurred. In doing so, it is likely that not many events have been missed.

More high-quality datasets are needed to incorporate other variables than only age and sex. Other determinants of life expectancy after AVR are coexisting CAD; left ventricular, pulmonary, and renal function; and other comorbid conditions such as malignancies or neurologic diseases. If these parameters were taken into account, the model would represent survival more tailored to the individual patient.

For now we can only perform a 1-way sensitivity analysis. It would be better to check the results in simulated outcome when the distributions of the input parameters are known. In this matter, work is in progress.

Microsimulation models are not yet widely known and used in the cardiothoracic fields, and they are not available in standard statistical software packages yet. The model described in this article is available by downloading the program along with instructions at www.cardiothoracicresearch.nl.

\section{CONCLUSIONS}

On the basis of the Vancouver dataset, it seems that even for patients aged 60 years who require AVR, the implantation of a bioprosthesis generally may be considered superior over a mechanical prosthesis. The risk of bleeding with a bioprosthesis is not absent, but compared with mechanical valves, the risk reduction of bleeding that can be achieved with a bioprosthesis outweighs the increased risk associated with SVD.

Comparing lifetime event risks between different types of valve prostheses provides more insight into patient outcome after AVR and aids in patient selection and counseling. When combined with careful assessment of individual patient preferences, this will provide a new key to optimized informed decision making.

\section{References}

1. Grunkemeier GL, Wu Y. Interpretation of nonfatal events after cardiac surgery: actual versus actuarial reporting. J Thorac Cardiovasc Surg. 2001;122: 216-9.

2. Chan V, Jamieson WR, Germann E, Chan F, Miyagishima RT, Burr LH, et al. Performance of bioprostheses and mechanical prostheses assessed by composites of valve-related complications to 15 years after aortic valve replacement. J Thorac Cardiovasc Surg. 2006;131:1267-73.

3. Takkenberg JJ, Puvimanasinghe JP, Grunkemeier GL. Simulation models to predict outcome after aortic valve replacement. Ann Thorac Surg. 2003;75: 1372-6.

4. Puvimanasinghe JP, Steyerberg EW, Takkenberg JJ, Eijkemans MJ, van Herwerden LA, Bogers AJ, et al. Prognosis after aortic valve replacement with a bioprosthesis: predictions based on meta-analysis and microsimulation. $\mathrm{Circu}$ lation. 2001;103:1535-41.

5. van Geldorp MW, Jamieson WR, Kappetein AP, Puvimanasinghe JP, Eijkemans MJ, Grunkemeier GL, et al. Usefulness of microsimulation to translate valve performance into patient outcome: patient prognosis after aortic valve replacement with the Carpentier-Edwards supra-annular valve. J Thorac Cardiovasc Surg. 2007; 134:702-9.

6. Edmunds LH Jr, Clark RE, Cohn LH, Grunkemeier GL, Miller DC, Weisel RD. Guidelines for reporting morbidity and mortality after cardiac valvular operations. Ad Hoc Liaison Committee for Standardizing Definitions of Prosthetic Hear Valve Morbidity of The American Association for Thoracic Surgery and The Society of Thoracic Surgeons. J Thorac Cardiovasc Surg. 1996;112:708-11.

7. Jamieson WR, Rosado LJ, Munro AI, Gerein AN, Burr LH, Miyagishima RT, et al. Carpentier-Edwards standard porcine bioprosthesis: primary tissue failure (structural valve deterioration) by age groups. Ann Thorac Surg. 1988;46: 155-62.

8. Grunkemeier GL, Li HH, Naftel DC, Starr A, Rahimtoola SH. Long-term performance of heart valve prostheses. Curr Probl Cardiol. 2000;25:73-154.

9. Thoman DR, Bain LJ, Antle CE. Influences on the parameters of the Weibull distribution. Technometrics. 1969;11:445-60.

10. van der Meer FJ, Rosendaal FR, Vandenbroucke JP, Briet E. Assessment of a bleeding risk index in two cohorts of patients treated with oral anticoagulants. Thromb Haemost. 1996;76:12-6.

11. Takkenberg JJ, Puvimanasinghe JPA, Van Herwerden LA, Steyerberg EW, Eijkemans MJC, Habbema JDF, et al. Prognosis after aortic valve replacement with St. Jude Medical bileaflet prostheses: impact on outcome of varying thromboembolic and bleeding hazards. Eur Heart J Suppl. 2001;3(Suppl Q):Q27-32.

12. Puvimanasinghe JP, Takkenberg JJ, Edwards MB, Eijkemans MJ, Steyerberg EW, Van Herwerden LA, et al. Comparison of outcomes after aortic valve replacement with a mechanical valve or a bioprosthesis using microsimulation. Heart. 2004;90:1172-8.

13. Steyerberg EW, Kallewaard M, van der Graaf Y, van Herwerden LA Habbema JD. Decision analyses for prophylactic replacement of the Bjork-Shiley convexo-concave heart valve: an evaluation of assumptions and estimates. Med Decis Making. 2000;20:20-32.

14. de Kruyk AR, van der Meulen JH, van Herwerden LA, Bekkers JA Steyerberg EW, Dekker R, et al. Use of Markov series and Monte Carlo simulation in predicting replacement valve performances. J Heart Valve Dis. 1998;7: 4-12.

15. Available at: www.sts.org, the Online STS Risk Calculator, The Society of Thoracic Surgeons. Accessed June 2007. 
16. Rankin JS, Hammill BG, Ferguson TB Jr, Glower DD, O’Brien SM, DeLong ER, et al. Determinants of operative mortality in valvular heart surgery. $J$ Thorac Cardiovasc Surg. 2006;131:547-57.

17. Available at: www.cdc.gov, Vital Statistics of the United States 1992, Centers for Disease Control and Provention and the National Center for Health Statistics. Accessed June 2007.

18. Available at: www.statisticscanada.ca, Statistics Canada. Accessed June 2007.

19. Available at: www.statistics.gov.uk, UK Statistics Authority. Accessed June 2007.

20. Kvidal P, Bergstrom R, Horte LG, Stahle E. Observed and relative survival after aortic valve replacement. J Am Coll Cardiol. 2000;35:747-56.

21. Gao G, Wu Y, Grunkemeier GL, Furnary AP, Starr A. Durability of pericardial versus porcine aortic valves. J Am Coll Cardiol. 2004;44:384-8.

22. Anon. The United Kingdom Heart Valve Registry Report (2000). London: UK Heart Valve Registry; 2002

23. Grunkemeier GL, Anderson RP, Miller DC, Starr A. Time-related analysis of nonfatal heart valve complications: cumulative incidence (actual) versus KaplanMeier (actuarial). Circulation. 1997;96(9 Suppl):II-70-5.

24. Grunkemeier GL, Jin R, Eijkemans MJ, Takkenberg JJ. Actual and actuarial probabilities of competing risks: apples and lemons. Ann Thorac Surg. 2007;83: 1586-92.

25. Jamieson WR, Burr LH, Miyagishima RT, Janusz MT, Fradet GJ, Ling H, et al. Re-operation for bioprosthetic aortic structural failure-risk assessment. Eur J Cardiothorac Surg. 2003;24:873-8.
26. Puvimanasinghe JP, Takkenberg JJ, Eijkemans MJ, Steyerberg EW, van Herwerden LA, Grunkemeier GL, et al. Choice of a mechanical valve or a bioprosthesis for AVR: does CABG matter? Eur J Cardiothorac Surg. 2003;23:688-95.

27. Bonow RO, Carabello BA, Kanu C, de Leon AC Jr, Faxon DP, Freed MD, et al. ACC/AHA 2006 guidelines for the management of patients with valvular heart disease: a report of the American College of Cardiology/American Heart Association Task Force on Practice Guidelines (writing committee to revise the 1998 Guidelines for the Management of Patients With Valvular Heart Disease): developed in collaboration with the Society of Cardiovascular Anesthesiologists: endorsed by the Society for Cardiovascular Angiography and Interventions and the Society of Thoracic Surgeons. Circulation. 2006; 114:e84-231.

28. Grube E, Laborde JC, Gerckens U, Felderhoff T, Sauren B, Buellesfeld L, et al. Percutaneous implantation of the CoreValve self-expanding valve prosthesis in high-risk patients with aortic valve disease: the Siegburg first-in-man study. Circulation. 2006;114:1616-24.

29. Lichtenstein SV, Cheung A, Ye J, Thompson CR, Carere RG, Pasupati S, et al. Transapical transcatheter aortic valve implantation in humans: initial clinical experience. Circulation. 2006;114:591-6.

30. Walther T, Falk V, Dewey T, Kempfert J, Emrich F, Pfannmuller B, et al. Valvein-a-valve concept for transcatheter minimally invasive repeat xenograft implantation. J Am Coll Cardiol. 2007;50:56-60. 


\section{Appendix E1.}

\section{Internal Validation}

The overall survival that was calculated by the model showed a slightly worse survival for both prosthesis groups than observed in the Vancouver dataset (Figure E1, A). When this dataset is split by different age groups, the differences between simulated and observed survival increase, especially in the older ages and more in the mechanical group than in the biological group (Figure E1, $B$ and $C$ ). Apparently the excess mortality is lower in the Vancouver dataset than it is in our model. An explanation may be that the microsimulation model predicts life expectancy a priori in a random patient, only knowing age and sex. The assumption is made that the excess mortality is equal for both patients who receive mechanical or bioprostheses. However, in clinical practice other patient characteristics are also taken into account in the valve selection process; patients with a better life expectancy are more likely to receive a mechanical valve, and patients with a decreased life expectancy are more likely to receive a bioprosthesis. This patient selection process is probably responsible for the differences between observed and simulated survival.

\section{External Validation}

Although simulated survival after AVR with a bioprosthesis corresponded with the Portland dataset (Figure E2, A), the simulated survival for the mechanical prostheses was again lower than the observed survival in the UK Heart
Valve Registry (Figure E2, B). The differences between the curves are considerable. Several factors can be responsible for this. First, patient selection is probably different among medical centers, countries, and continents. Second, prosthesis types and brands will differ between medical centers, but it is questionable whether this factor contributes much to the observed survival differences. Third, background mortality is different between different countries. This clearly influences life expectancy after AVR, as is shown in Figure 1. However, difference in background mortality has hardly any influence on the point of indifference for the event-free life expectancy curves for both prostheses. To show this, we simulated patients after AVR using both background mortalities from the United States and British Columbia, Canada. The effect on event-free life expectancy is displayed in Figure E3, A. The curves will only shift upward or downward, but the age cutoff point at which a bioprosthesis is preferable over a mechanical prosthesis remains the same. This finding implies that the conclusions drawn from this article would remain the same for patients from British Columbia or patients from other Western countries, such as the United Kingdom. Figure E3, $B$ is a detail of Figure 3 and Figure E3, $A$ and displays the crossing point of the event-free life expectancy curves. The $68 \%$ confidence limits around the event-free life expectancy curves of the mechanical and bioprosthesis groups are also given The crossing $68 \%$ confidence limits demarcate the area in which the real crossing point of the event-free life expectancy curves lies (with a $95 \%$ certainty). 

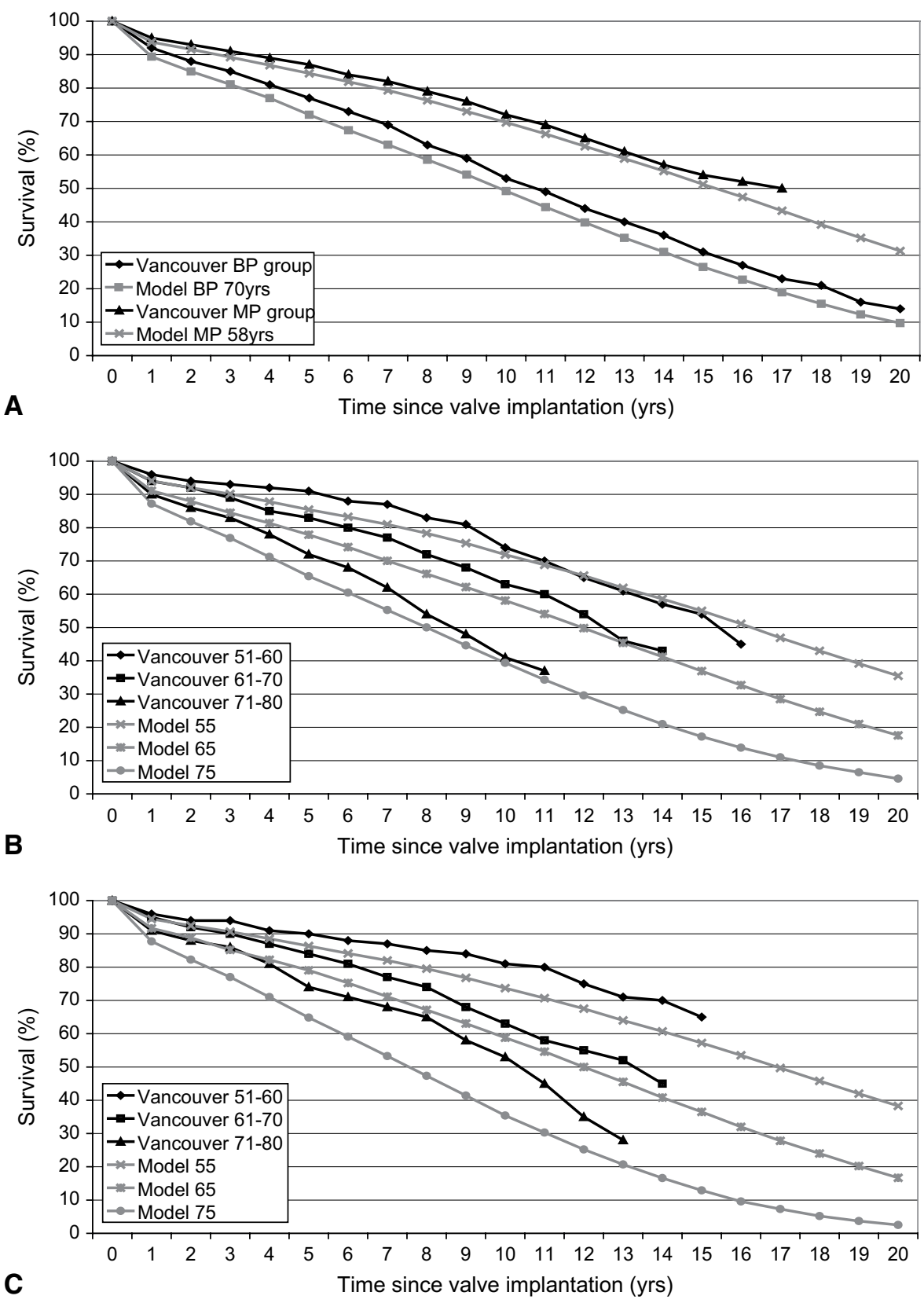

FIGURE E1. Internal validation. A, Simulated survival of 58-year-old patients who received mechanical bioprostheses and 70-year-old patients who received bioprostheses versus total observed survival in the biological and mechanical prostheses groups of the Vancouver dataset. B, Simulated survival of 55-, 65-, and 75-year-old male patients with a bioprosthesis versus the bioprosthesis group of the Vancouver dataset, subdivided in age categories. C, Simulated survival of 55-, 65-, and 75-year-old male patients with a mechanical prosthesis versus the mechanical prosthesis group of the Vancouver dataset, subdivided in age categories. $M P$, mechanical prosthesis; $B P$, biological prosthesis. 

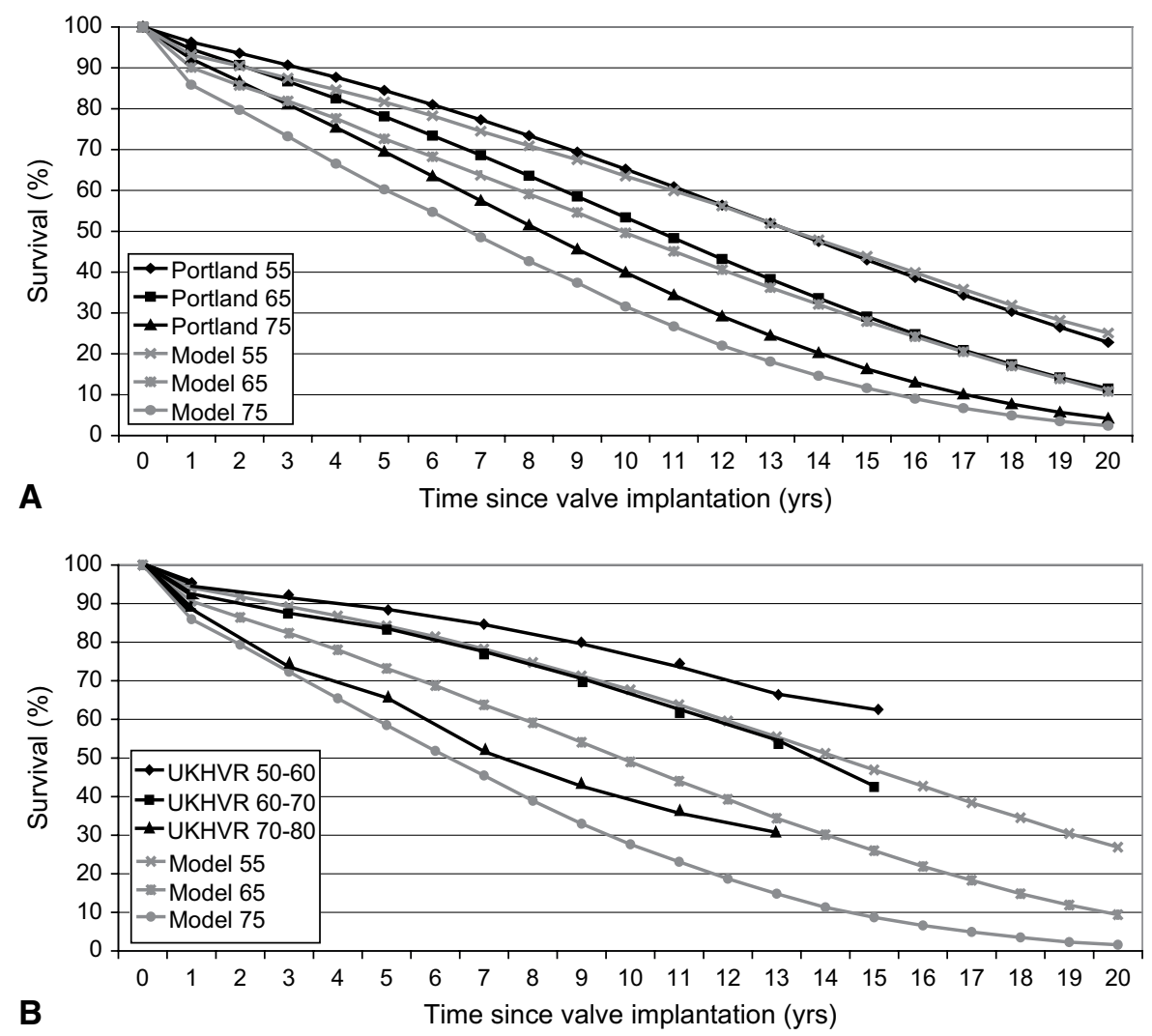

FIGURE E2. External validation. A, Simulated survival of 55-, 65-, and 75-year-old male patients with a bioprosthesis versus the observed survival in the Portland dataset, subdivided in age categories. B, Simulated survival of 55-, 65-, and 75-year-old male patients with a mechanical prosthesis versus the observed survival in the United Kingdom Heart Valve Registry mechanical dataset, subdivided in age categories. UKHVR, United Kingdom Heart Valve Registry. 

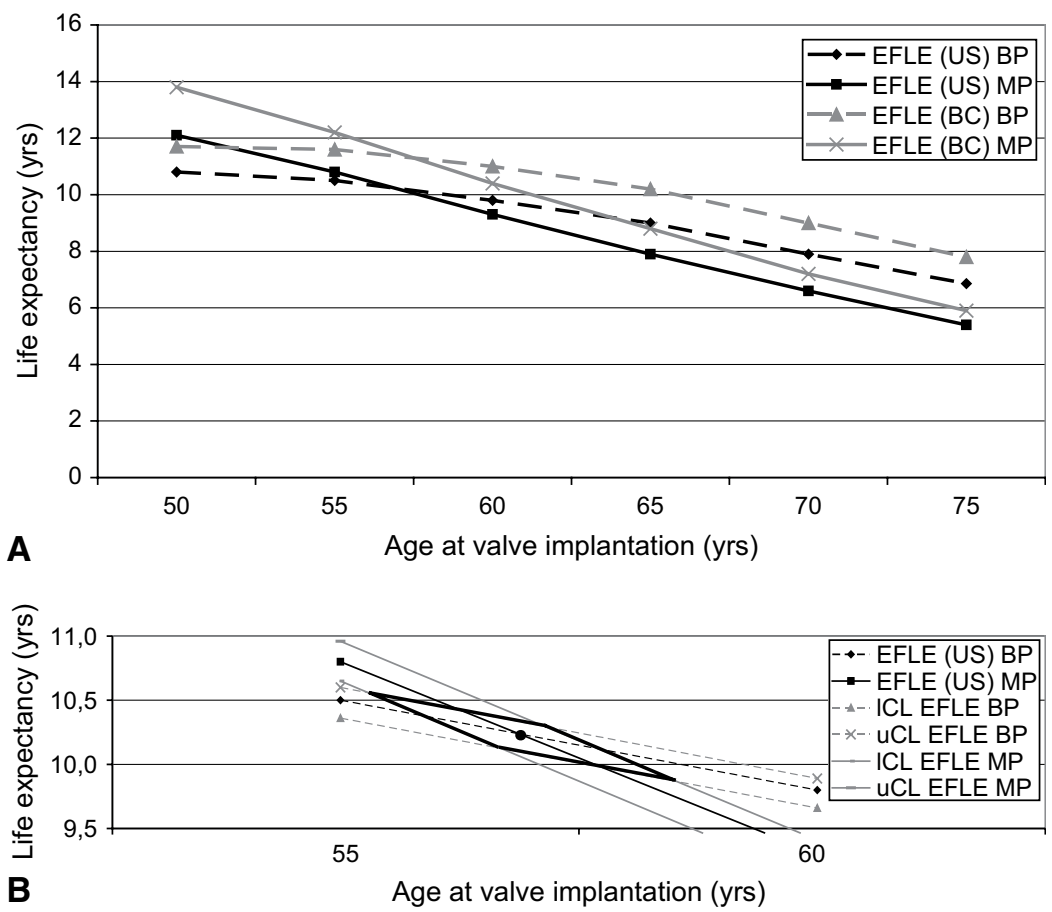

FIGURE E3. Event -free life expectancy for men at different ages of valve implantation. A, Event-free life expectancy for men with a mechanical valve (solid lines) versus a bioprosthesis (dotted lines). Black lines represent the United States population; grey lines represent the population in British Columbia, Canada. Background mortality changes among different populations, which has an effect on absolute event-free life expectancy but hardly any effect on the age cutoff point at which a bioprosthesis is preferable over a mechanical prosthesis. B, Detail of Figures 3 and E3, A. The crossing points of the $68 \%$ confidence limits around the event-free life expectancy curves demarcate the area in which the real event-free life expectancy age cutoff point lies (with a $95 \%$ certainty). $M P$, Mechanical prosthesis; $B P$, biological prosthesis. EFLE, event-free life expectancy.

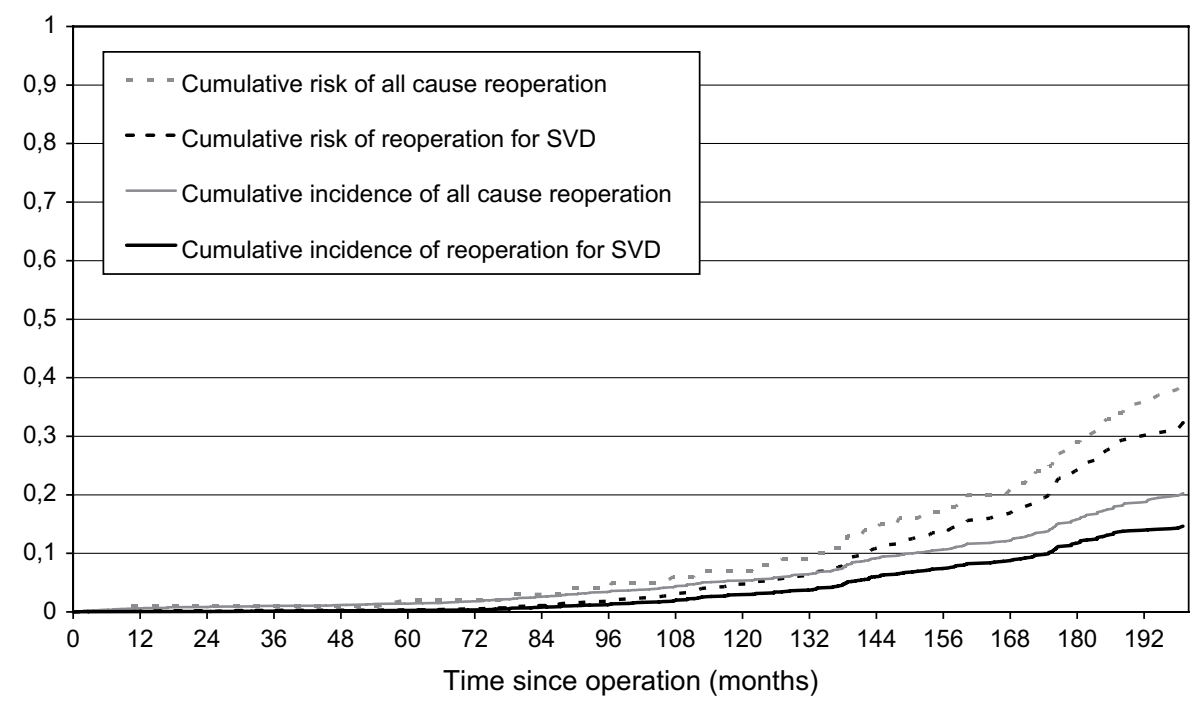

FIGURE E4. Actual versus actuarial analysis of all-cause reoperation and reoperation for SVD in the biological group of the Vancouver dataset. SVD, Structural valve deterioration. 
TABLE E1. Input microsimulation model, directly derived from the Vancouver dataset

\begin{tabular}{|c|c|c|c|c|c|c|c|c|c|c|c|c|}
\hline \multirow[b]{2}{*}{ Valve-related event } & \multicolumn{2}{|c|}{$\mathbf{n}$} & \multicolumn{2}{|c|}{$\begin{array}{c}\text { Linearized } \\
\text { occurrence rate }^{a}\end{array}$} & \multicolumn{2}{|c|}{$\begin{array}{c}\text { Fatalities if no } \\
\text { reoperation }\end{array}$} & \multicolumn{2}{|c|}{$\begin{array}{l}\text { Mortality } \\
\text { rate }\end{array}$} & \multicolumn{2}{|c|}{$\begin{array}{c}\text { No. of } \\
\text { reoperations }\end{array}$} & \multicolumn{2}{|c|}{$\begin{array}{c}\text { Reoperation } \\
\text { rate }^{c}\end{array}$} \\
\hline & BP & MP & $\begin{array}{c}\text { BP }(17,352 \\
\text { patient-y })\end{array}$ & $\begin{array}{l}\text { MP }(9115 \\
\text { patient-y) }\end{array}$ & BP & MP & BP & MP & BP & MP & BP & MP \\
\hline Bleeding & 92 & 202 & 0.53 & Gompertz & 34 & 33 & 0.37 & 0.16 & 0 & 0 & 0 & 0 \\
\hline $\begin{array}{l}\text { Nonstructural } \\
\text { dysfunction }\end{array}$ & 40 & 41 & 0.23 & 0.45 & 2 & 4 & 0.05 & 0.10 & 35 & 16 & 0.92 & 0.43 \\
\hline $\begin{array}{l}\text { Prosthetic valve } \\
\text { endocarditis (late) }\end{array}$ & $53(46)$ & $16(7)$ & $\begin{array}{r}2 \text { periods } \\
(0.29)\end{array}$ & $\begin{array}{l}2 \text { periods } \\
(0.082)\end{array}$ & 18 & 1 & 0.34 & 0.06 & 20 & 9 & 0.57 & 0.60 \\
\hline $\operatorname{SVD}^{\mathrm{d}}$ & 137 & 0 & Weibull & 0 & 0 & NA & 0 & NA & 137 & NA & 1.0 & NA \\
\hline Thromboembolism & 219 & 121 & 1.26 & 1.33 & 72 & 28 & 0.33 & 0.23 & 0 & 0 & 0 & 0 \\
\hline Valve thrombosis & 7 & 5 & 0.04 & 0.06 & 0 & 1 & 0 & 0.20 & 7 & 2 & 1.0 & 0.50 \\
\hline $\begin{array}{l}\text { Sudden unexpected } \\
\text { Unexplained death }^{\mathrm{e}}\end{array}$ & 15 & 7 & NA & NA & NA & NA & NA & NA & NA & NA & NA & NA \\
\hline Total & 585 & 392 & & & 126 & 67 & & & 199 & 27 & & \\
\hline
\end{tabular}

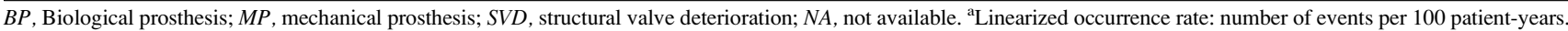
${ }^{\mathrm{b}}$ Number of fatalities if no reoperation was performed (either because patient died before or after decision not to operate). ${ }^{\mathrm{c}}$ Proportion who underwent reoperation after surviving the event in the first place (no. reoperations/[no. events—no. fatalities]). 'SVD was defined as "reoperation because of SVD" and therefore has no direct fatalities. 'The cases of sudden unexpected unexplained death were entered into the model as part of the "excess mortality."

TABLE E2. Sensitivity analysis for a 60-year-old American man after aortic valve replacement with a bioprosthesis

\begin{tabular}{|c|c|c|c|c|c|c|c|c|c|}
\hline \multirow{3}{*}{$\begin{array}{c}\text { Valve-related } \\
\text { event }\end{array}$} & \multicolumn{3}{|c|}{ Input } & \multicolumn{6}{|c|}{ Output } \\
\hline & \multirow{2}{*}{$\begin{array}{c}\text { Linearized } \\
\text { occurrence } \\
\text { rate } \\
\text { (baseline) }\end{array}$} & \multirow{2}{*}{$\begin{array}{l}\text { Linearized } \\
\text { occurrence } \\
\text { rate }-25 \% \\
\text { (favorable) }\end{array}$} & \multirow{2}{*}{$\begin{array}{c}\text { Linearized } \\
\text { occurrence } \\
\text { rate }+25 \% \\
\text { (unfavorable) }\end{array}$} & \multicolumn{2}{|c|}{$\begin{array}{c}\text { Life } \\
\text { expectancy }\end{array}$} & \multicolumn{2}{|c|}{$\begin{array}{c}\text { Event-free life } \\
\text { expectancy }\end{array}$} & \multicolumn{2}{|c|}{$\begin{array}{c}\text { Reoperation-free life } \\
\text { expectancy }\end{array}$} \\
\hline & & & & Favorable & Unfavorable & Favorable & Unfavorable & Favorable & Unfavorable \\
\hline Bleeding & 0.53 & 0.40 & 0.66 & 12.1 & 11.9 & 9.9 & 9.7 & 10.6 & 10.5 \\
\hline $\begin{array}{l}\text { Nonstructural } \\
\text { dysfunction }\end{array}$ & 0.23 & 0.17 & 0.29 & 12.1 & 12.1 & 9.9 & 9.8 & 10.7 & 10.6 \\
\hline $\begin{array}{c}\text { Prosthetic valve } \\
\text { endocarditis }\end{array}$ & 0.29 & 0.22 & 0.36 & 12.2 & 12.1 & 9.9 & 9.8 & 10.7 & 10.6 \\
\hline $\mathrm{SVD}^{\mathrm{a}}$ & 22.0 & 27.5 & 16.5 & 10.6 & 10.3 & 9.3 & 8.4 & 10.0 & 8.9 \\
\hline Thromboembolism & 1.26 & 0.95 & 1.58 & 12.2 & 12.0 & 10.1 & 9.6 & 10.7 & 10.6 \\
\hline Valve thrombosis & 0.04 & 0.03 & 0.05 & 12.1 & 12.1 & 9.9 & 9.9 & 10.7 & 10.6 \\
\hline Operative mortality & $5.0 \%$ & $3.8 \%$ & $6.3 \%$ & 12.1 & 11.8 & 9.9 & 9.6 & 10.7 & 10.4 \\
\hline Hazard ratio & 1.2 & 0.9 & 1.5 & 12.9 & 11.3 & 10.3 & 9.4 & 11.2 & 10.1 \\
\hline
\end{tabular}

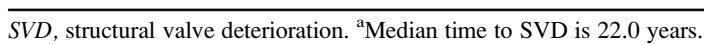

TABLE E3. Sensitivity analysis for a 60-year-old American man after aortic valve replacement with a mechanical prosthesis

\begin{tabular}{|c|c|c|c|c|c|c|c|c|c|}
\hline \multirow{3}{*}{$\begin{array}{c}\begin{array}{c}\text { Valve-related } \\
\text { event }\end{array} \\
\end{array}$} & \multicolumn{3}{|c|}{ Input } & \multicolumn{6}{|c|}{ Output } \\
\hline & \multirow{2}{*}{$\begin{array}{c}\text { Linearized } \\
\text { occurrence } \\
\text { rate } \\
\text { (baseline) } \\
\end{array}$} & \multirow{2}{*}{$\begin{array}{c}\text { Linearized } \\
\text { occurrence } \\
\text { rate }-\mathbf{2 5} \% \\
\text { (favorable) } \\
\end{array}$} & \multirow{2}{*}{$\begin{array}{c}\text { Linearized } \\
\text { occurrence } \\
\text { rate }+\mathbf{2 5} \% \\
\text { (unfavorable) } \\
\end{array}$} & \multicolumn{2}{|c|}{$\begin{array}{c}\text { Life } \\
\text { expectancy }\end{array}$} & \multicolumn{2}{|c|}{$\begin{array}{c}\text { Event-free life } \\
\text { expectancy }\end{array}$} & \multicolumn{2}{|c|}{$\begin{array}{c}\text { Reoperation-free life } \\
\text { expectancy }\end{array}$} \\
\hline & & & & Favorable & Unfavorable & Favorable & Unfavorable & Favorable & Unfavorable \\
\hline Bleeding & Gompertz & & & 12.9 & 8.7 & 11.0 & 4.1 & 12.6 & 8.5 \\
\hline $\begin{array}{l}\text { Nonstructural } \\
\text { dysfunction }\end{array}$ & 0.45 & 0.34 & 0.56 & 12.2 & 12.2 & 9.3 & 9.2 & 12.0 & 11.9 \\
\hline $\begin{array}{c}\text { Prosthetic valve } \\
\text { endocarditis }\end{array}$ & 0.08 & 0.06 & 1.0 & 12.2 & 12.2 & 9.3 & 9.2 & 12.0 & 11.9 \\
\hline SVD & NA & NA & NA & NA & NA & NA & NA & NA & NA \\
\hline Thromboembolism & 1.33 & 1.00 & 1.66 & 12.3 & 12.1 & 9.5 & 9.1 & 12.0 & 11.9 \\
\hline Valve thrombosis & 0.06 & 0.04 & 0.07 & 12.2 & 12.2 & 9.3 & 9.3 & 12.0 & 11.9 \\
\hline Operative mortality & $5.0 \%$ & $3.8 \%$ & $6.3 \%$ & 12.1 & 11.8 & 9.9 & 9.6 & 10.7 & 10.4 \\
\hline Hazard ratio & 1.2 & 0.9 & 1.5 & 12.9 & 11.4 & 9.7 & 8.8 & 12.7 & 11.2 \\
\hline
\end{tabular}

$S V D$, Structural valve deterioration; $N A$, not available. 